DOI 10.37882/2500-3682.2020.11.26

\title{
ИССЛЕДОВАНИЕ ПРОФЕССИОНАЛЬНЫХ СКЛОННОСТЕЙ К ПРЕДПРИНИМАТЕЛЬСКОЙ ДЕЯТЕЛЬНОСТИ У МОЛОДЕЖИ РЕСПУБЛИКИ ХАКАСИЯ
}

\section{A STUDY OF PROFESSIONAL DISPOSITIONS TO BUSINESS ACTIVITIES YOUNG PEOPLE OF THE REPUBLIC OF KHAKASSIA}

\author{
T. Fotekova \\ S. Mitrukhina \\ E. Vlasova \\ A. Fedorova \\ A. Mantikova
}

Summary: The article presents the results of an experimental study of the predisposition to entrepreneurial activity in young people aged 1930 years, including those receiving higher and secondary professional education, living in the Republic of Khakassia. Based on the abstract study and review of the literature on the problem of entrepreneurial abilities, a generalized model of a modern entrepreneur and a program for diagnostics (assessment) of professional predisposition to entrepreneurial activity were compiled. Personal and professionally important qualities of an entrepreneur (future entrepreneur) were grouped into 5 clusters, the content of which is filled with qualities. The developed psychodiagnostic complex was tested on a sample of subjects.

Keywords: entrepreneurial inclinations, entrepreneurial motives, entrepreneurial goals, entrepreneurial intent, model, professionally important qualities of an entrepreneur.
Фотекова Татьяна Анатольевна

Д.nсх.н., профессор, ФГБОУ ВО «Хакасский государственный университет им. Н.Ф. Катанова» (г.Абакан)

fotekova@yandex.ru

Митрухина Светлана Владимировна

ФГБОУ ВО «Хакасский государственный университет им. Н.Ф. Катанова» (2.Абакан) mitruhina_lana80@mail.ru

Власова Евгения Николаевна

к.nсх.н., доцент, ФГБОУ ВО «Хакасский государственный университет им. Н.Ф. Катанова» (г.Абакан) vlasova6510@gmail.com

Федорова Анжелика Алексеевна к.nсх.н., дочент, ФГБОУ ВО «Хакасский государственный университет им. Н.Ф. Катанова» (г.Абакан) alis151@yandex.ru

Мантикова Анна Владимировна старший преподаватель, ФГБОУ ВО «Хакасский государственный университет им. Н.Ф. Катанова»

(2.Абакан)

anetdomanet@mail.ru

Аннотация: В статье представлены результаты экспериментального исследования предрасположенности к предпринимательской деятельности у молодых лиц 19-30 лет, в том числе получающих высшее и среднее профессиональное образование, проживающих в Республике Хакасия. На основе реферативного изучения и обзора литературы по проблеме предпринимательских способностей была составлена обобщённая модель современного предпринимателя и программа диагностики (оценки) профессиональной предрасположенности к предпринимательской деятельности. Личностные и профессионально-важные качества будущего предпринимателя были сгруппированы в 5 кластеров, содержание которых наполнено качествами. Разработанный психодиагностический комплекс апробирован на многочисленной выборке испытуемых.

Ключевые слова: предпринимательские склонности, предпринимательские мотивы, предпринимательские цели, предпринимательская интенция, модель, профессионально-важные качества предпринимателя.

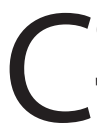

овременные социально-экономические условия диктуют необходимость развития качеств делового человека - предпринимателя. Общество «процветания» и высокого уровня жизни немыслимо без предпринимательских усилий.

Предпринимательство - явление экономической жизни общества, это общественно-хозяйственный процесс создания нового, имеющего социальную, духовную, экономическую ценность. Этот процесс забирает силу и время, предполагает принятие на себя моральной, юридической, социальной и экономической ответственности, он приносит прибыль и удовлетворение достигнутым. Предпринимательская деятельность - составная часть этого процесса.

Исследованием предпринимательства и предпринимательских способностей занимались такие ученые как Р. Кантильон, А. Смит, Ж.Б. Сэй, Дж.С. Мил, В. Зомбарт, П. Дракер, Й. Шумпетер и др. 
В некоторых современных работах по экономической теории (Ж.Б. Сэй, А. Маршал и др.), предпринимательские способности отдельно рассматриваются как фактор производства особого рода, наряду с тремя классическими (труд, земля, капитал). Эти способности характеризуют деятельность по рациональной комбинации остальных факторов производства. Носителями предпринимательских способностей в рыночной экономике являются непосредственно предприниматели люди, организующие новое дело.

Предпринимательские способности можно считать особым видом человеческого капитала, представленного деятельностью по координации и комбинированию всех основных факторов производства.

Теоретической и методологической базой исследования являются системный (В.А. Барабанщиков, Б.Ф. Ломов, В.Д.Шадриков и др.) и деятельностный (С.Л. Рубинштейн, А.Н. Леонтьев, В.В. Давыдов, Т.В. Габай, В.И. Слободчиков) подходы, фундаментальные работы отечественных и зарубежных психологов по проблемам психологии предпринимательства (Д. Макклеланд, Р. Хизрич, М. Питере, В.В. Новиков, И. Шумпетер, Р. Брокхаус, М. Кете, А.Л. Журавлев, В.П. Позняков, А.В. Карпов, Т.Ю. Базаров, В.В. Марченко и др.); социальной психологии (Г.М.Андреева, В.В.Новиков, А.И.Донцов,А.Л.Свенцицкий, А.Л. Журавлев, И.П. Волков, Е.В. Шорохова и др.) и успешности профессиональной деятельности (Е.А. Климов, О.Н. Родина, Н.В. Самоукина, Б.М. Теплов и др.).

Психологическое изучение склонности и последующее стимулирование молодежи к предпринимательской деятельности в будущем может оказать существенное влияние на стабилизацию экономической ситуации и развитие института предпринимательства. Сегодня перед образовательными учреждениями стоит задача решить проблемы занятости выпускников, в том числе через формирование психологической готовности молодежи к предпринимательской деятельности.

Результаты исследования предпринимательства показывают, что большинство людей намерены заниматься предпринимательской деятельностью в более молодом возрасте. В связи с этим важным аспектом в изучении предпринимательства является исследование молодежного предпринимательства (в том числе среди студентов), ведь именно на этом жизненном этапе начинает формироваться предпринимательское сознание и отношение молодых людей к предпринимательской деятельности.

С целью оценки предрасположенность в предпринимательской деятельности молодежи нами было проведено исследование среди молодых людей 19-30 лет, в том числе получающих высшее и среднее профессиональное образование, проживающих в Республике Хакасия.

Методологической основой исследования выступили теоретические положения Климовой Е.К. и выделенные ею критерии склонности к предпринимательской деятельности [5].

Климова Е.К. рассматривает следующие критерии склонности к предпринимательской деятельности [5]:

- предпринимательские мотивы - высокие показатели по критерию свидетельствуют о наличии у субъекта стремления заниматься предпринимательской деятельностью, в первую очередь, в связи с интересом к творческой, близкой ему по духу деятельности, под воздействием потребности в самореализации. Средние - говорят о том, что потребность в самореализации не является ведущей при намерении индивида заниматься предпринимательской деятельностью; низкие об отсутствии у индивида внутренних мотивов при освоении или осуществлении предпринимательской деятельности.

- предпринимательские цели - высокие показатели по критерию указывают на целенаправленность деятельности предпринимателя, на высокий уровень его готовности к проявлению настойчивости в достижении поставленных целей. Средние показатели свидетельствуют о наличии у индивида целей, косвенно связанных с содержанием предпринимательской деятельности и не соответствующих потребности в самореализации в этой деятельности. Для предпринимателя «создание или развитие предприятия» является не целью, а средством достижения других целей (например, заработать много денег для обеспечения будущего детей). Низкие - говорят об отсутствии целенаправленности в предпринимательской активности индивида, о невысокой настойчивости в достижении предпринимательских целей;

- предприимчивость - высокие показатели по этому критерию свидетельствуют о ярко выраженной предприимчивости у человека - способности проявлять деловую активность, инициативность В предпринимательской деятельности; способности быстро принимать решения и действовать в условиях неопределенности. Чем выше показатели, тем сильнее выражена предприимчивость у человека;

- стратегическое мышление - критерий отражают способность индивида прогнозировать развитие рыночной ситуации, видеть образ будущего в ситуациях неопределённости, осознавать момент и точку приложения сил, заслуживающих риска, способность в затруднительных предпринимательских ситуациях «соседствовать» с проблемой и строить проблемную ситуацию по-новому. Чем 
выше показатели, тем более развито стратегическое мышление у человека;

- стрессоустойчивость - показатели по критерию отражают готовность индивида продуктивно трудиться в напряжённых, неопределённых и стрессовых ситуациях. Высокие показатели свидетельствуют о высокой степени выраженности данного качества у субъекта, и наоборот, низкие - говорят о низкой стрессоустойчивости человека.

- предпринимательская интенция - критерий отражает степень выраженности предпринимательских намерений у индивида. Человек, с высоким уровнем предпринимательской интенции, побуждается к деятельности, в первую очередь, мотивом достижения успеха в предпринимательской деятельности. Он ставит предпринимательские цели и проявляет высокую настойчивость в их достижении. Такой специалист способен испытывать чувство удовлетворения не только от результата предпринимательской деятельности, но также от её процесса и предвосхищения. Чем выше показатели, тем больше степень выраженности предпринимательских намерений у индивида;

- предпринимательские ресурсы - критерий отражает, насколько у субъекта развиты профессионально-важные качества (предприимчивость, стратегическое мышление и стрессоустойчивость), необходимые для успешного осуществления предпринимательской деятельности. Чем выше показатели, тем более развиты соответствующие предпринимательские ресурсы у субъекта.

Интегральным показателем предпринимательских способностей является «психологическая готовность к предпринимательской деятельности», которая свиде- тельствует о степени освоения предпринимательской деятельности в целом. Чем выше показатели по этому критерию, тем выше степень освоения структурно-динамических элементов предпринимательской деятельности (мотивов, целей и ресурсов), а, следовательно, выше вероятность достижения успеха в осуществлении данной деятельности.

Предпринимательская компетентность представляет собой систему элементов, объединенных множеством связей как друг с другом, так и с внешней макросредой. В ходе разработки темы нами проведён экспертный анализ и отбор личностных и профессионально-важных качеств предпринимателя; отсортированные личностные и профессионально-важные качества сгруппированы в 5 кластеров, содержание которых наполнено качествами (факторами потенциала успешности предпринимательской деятельности) (рисунок 1).

Разработанный пакет диагностического инструментария позволяет надёжно, достоверно исследовать профессиональную предрасположенность к предпринимательской деятельности как потенциал личности, а не как самооценку респондентов. Именно поэтому нами был исключён опросный метод и метод шкалирования самооцениванием, который не может обеспечить валидности, надёжности, достоверности полученных результатов в силу субъективизма процесса самооценивания. Вместо этого использованы проективные методики, их модификации и метод решения проблемных ситуаций в виде кейсов.

Успешность предпринимательской деятельности возможна в случае выраженности у личности всех пяти кластеров на высоком уровне, и будет снижаться с
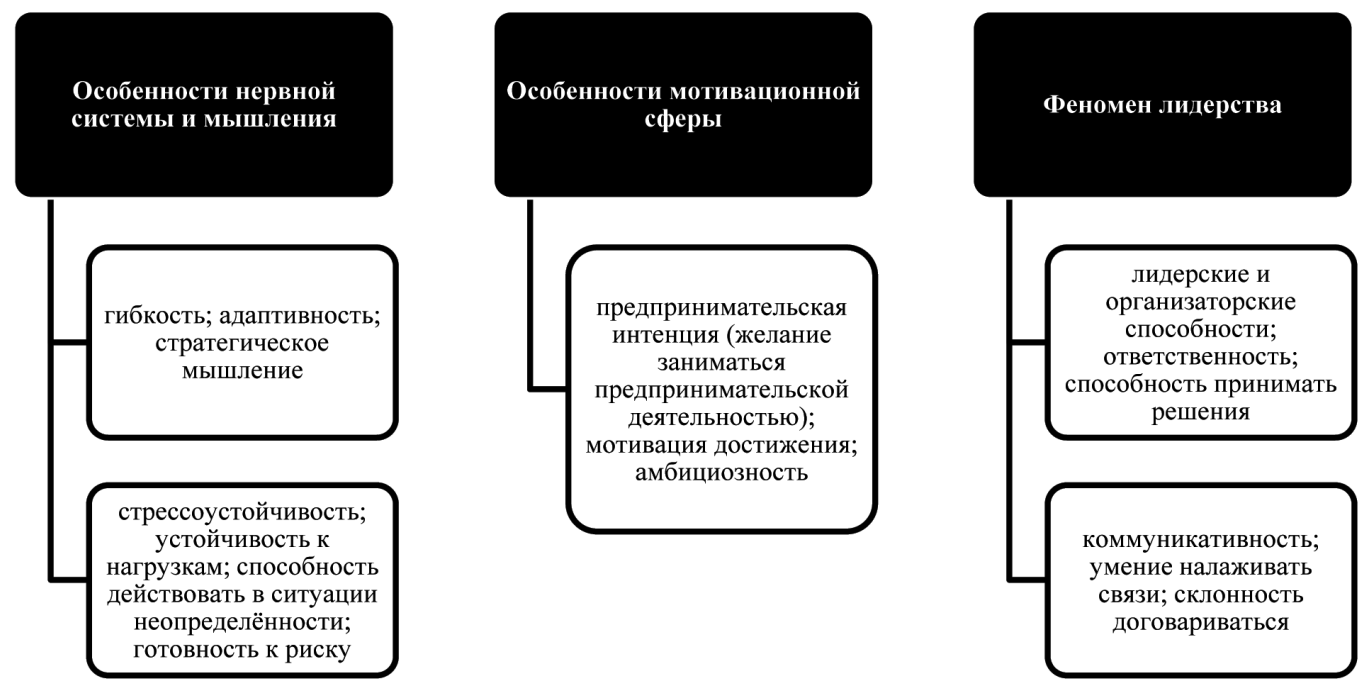

Рис. 1. Модель личностных качеств, определяющих склонность к предпринимательской деятельности. 
уменьшением списка выраженных профессиональноважных качеств. Если хотя бы один из кластеров не заполнен - прогноз успешности в предпринимательстве отрицательный.

В диагностический пакет были включены:

- отобранные кейсы из методики Климовой Е.К. Ситуационный опросник «Диагностика психологической готовности к предпринимательской деятельности» [5];

- конструктивный рисунок человека из геометрических фигур (авторская модификация);

- проективный тест «Моё настоящее и будущее» на амбициозность,

- лидерские черты (авторская модификация проективного теста «Карьерная перспектива»);

- проективный тест «Предпринимательские способности»;

- психогеометрический тест [13] (авторская модификация).

Обобщив все полученные данные и высчитав суммарный показатель, учтя также основные параметры распеределения данных, а именно среднее значение и стандартное отклонение, мы выделили три уровня выраженности предпринимательских склонностей: 1 уровень, склонности отсутствуют - 6 баллов и ниже; 2 уровень, склонности выражены слабо - от 7 до 12 баллов; 3 уровень - имеются склонности к предпринимательской деятельности - от 13 баллов и выше.

Статистическая обработка полученных данных производилась с использованием описательных статистик, анализа частот, однофакторного дисперсионного анализа ANOVA, и апостериорных критериев. Применялся пакет программ IBM SPSS Statistics 20.

Группа обследуемых включала молодёжь в возрасте от 19 до 30 лет, в том числе получающую высшее или среднее профессиональное образование. Всего было обследовано 1367 человек: 62\% из них составили женщины и 38\% мужчины. Обследованные молодые люди обучались в 9 структурных подразделениях ФГБОУ ВО «Хакасский государственный университет им. Н. Ф. Катанова», в Хакасском техническом институте - филиале ФГАОУ ВО «Сибирский федеральный университет» и 8 колледжах (образовательных учреждениях среднего профессионального образования) Республики Хакасия. Самой многочисленной оказалась группа будущих врачей (16,5\%), юристов (6,9\%), педагогов начального и дошкольного образования (6,6\%), специалистов в области информатики и вычислительной техники (5,7\%). Среди молодых людей были представители всех административно-территориальных образований Республики Хакасия, но больше всего (73\%) - жителей города Абакан.
При анализе конструктивного рисунка человека, выполненного испытуемыми, были выявлены следующие результаты: у молодых людей плохо развита ответственность, лидерские и организаторские способности и умение принимать решение, т.е. качества в соответствие с нашей моделью относимые к феномену лидерства. Однако испытуемые этой группы достаточно гибкие, адаптивные и могут действовать в ситуации неопределенности, т.е. обладают необходимыми для предпринимательской деятельности свойствами нервной системы. Анализ индивидуальных значений обнаружил, что лидерские качества ответственность и способность принимать решения присущи 4,1\% молодых людей, а гибкость, адаптивность и стратегическое мышление наблюдается у $27,7 \%$.

Самым распространенным среди молодых людей 1930 лет оказался тип «изобретатель, конструктор, художник», который, характеризуется гибкостью и адаптивностью, а также способностью действовать в ситуации неопределенности. Такие характеристики можно соотнести со склонностью к предпринимательству, и они выявлены у 24,7\% протестированных представителей молодежи. Наиболее тесно связанный с предпринимательством тип «руководитель» встречается очень редко, всего у $4,1 \%$ испытуемых.

Проективный тест «Мое настоящее и будущее» обнаружил следующие особенности: 36,6\% молодых людей обладают амбициозностью, мотивация достижения характерна для 20,2\%, при этом лидерские черты оказались выше, чем в предыдущем тесте и характеризуют 19,2\% испытуемых в возрасте от 19 до 30 лет.

Выполняя тест, требующий закончить изображение, молодые люди показали следующие результаты: предприимчивостью обладают 40,8\% молодых людей, адаптивность характерна для 39,7\%, а стратегическое мышление встречается реже, лишь у 13,5\% обследованных людей данной возрастной категории.

Лидерские и организаторские качества продемонстрировали по итогам этой диагностической процедуры 33,2\% молодых людей, способность принимать решения присущи 33,5\% из них, коммуникативные качества, умение договариваться и налаживать связи характерны для 38\%, 37,7\% представителей данной группы устойчивы к нагрузкам, 37,1\% ответственны. Предрасположенность к предпринимательской деятельности выявлена лишь у 6,5\% испытуемых данной категории.

Результаты применения модифицированного ситуационного опросника психологической готовности к предпринимательской деятельности показали, что явные предпринимательские мотивы выявлены только у 7,76\% опрошенных, а для 52,3\% они совсем 
не характерны. Предпринимательские цели присутствуют у 33\% молодых людей и у 20,5\% их нет вообще. Предприимчивость свойственна 36,4\% молодых людей и совсем не свойственна 17,3\%. Стратегическое мышление присуще 18,4\% и не характерно для 36,9\% испытуемых в возрасте от 19 до 30 лет. Низкая стрессоустойчивость должна рассматриваться как помеха предпринимательству, она выявлена у 36,1\% молодых людей, а высокая стрессоустойчивость наблюдается только у 17,5\%. Предпринимательские мотивы и цели в совокупности определяют предпринимательскую интенцию, которая явно выражена у 5\% обследованных, присутствует еще у $16 \%$ и у $12,6 \%$ молодых людей ее совсем нет. Предпринимательские ресурсы также не очень развиты у молодежи: их высокий уровень (6 баллов) обнаружен только у 2,9\%, чуть меньше (5 баллов) эти ресурсы присутствуют еще у 8,4\%, но у 17,4\% молодых людей таких ресурсов нет (0-1 балл).

Итак, итоговый показатель психологической готовности к предпринимательской деятельности у молодежи, проживающей в Республике Хакасия (см. рисунок 2), выражен слабо, высокий уровень готовности продемонстрировали по итогам тестирования 6,2\% (8-10 баллов) и около 5\% характеризуются полным отсутствием такой готовности.

На рисунке 3 представлен профиль выраженности профессионально важных для предпринимательской деятельности качеств у лиц 19-30 лет. На профиле видно, что высокие показатели характеризуют только предприимчивость, в то время как на низком уровне находятся лидерство, ответственность и способность принимать решения. Профили молодых людей и старшеклассников практически идентичны.
Обобщив все показатели, мы можем проанализировать распределение обследованных молодых людей по выделенным нами трем уровням предпринимательских склонностей: предрасположенность к предпринимательской деятельности присутствует у 15,95\% молодых людей и совсем не характерна для $22,8 \%$.

Поскольку значительная часть представителей этой группы обучается в вузах на разных специальностях, мы может проанализировать связь направления обучения с выраженностью предпринимательских склонностей. Для упрощения процедуры анализа мы сравнили итоговый показатель предпринимательских склонностей у студентов разных направлений и специальностей. Было выявлено, что этот показатель несколько выше у тех, кто обучается по направлениям и специальностям «строительство», «техносферная безопасность», «психология», а также «музыка и теория художественной культуры», однако однофакторный дисперсионный анализ показывает, что эти различия не достигают статистически значимого уровня.

Таким образом, в нашем исследовании не обнаружено связи между предпринимательскими склонностями и направлением подготовки или специальностью. Также не обнаружено корреляции предпринимательских склонностей с местом жительства. Молодые люди, проживающие в разных административно-территориальных образованиях Республики Хакасия статистически не различаются по уровню предпринимательских склонностей, также не выявлены нами и подтвержденные статистическим анализом половые различия.

Данные, полученные в ходе обследования, могут стать основой для обоснования необходимости разработки региональных программ, направленных стимулирование предпринимательской активности среди

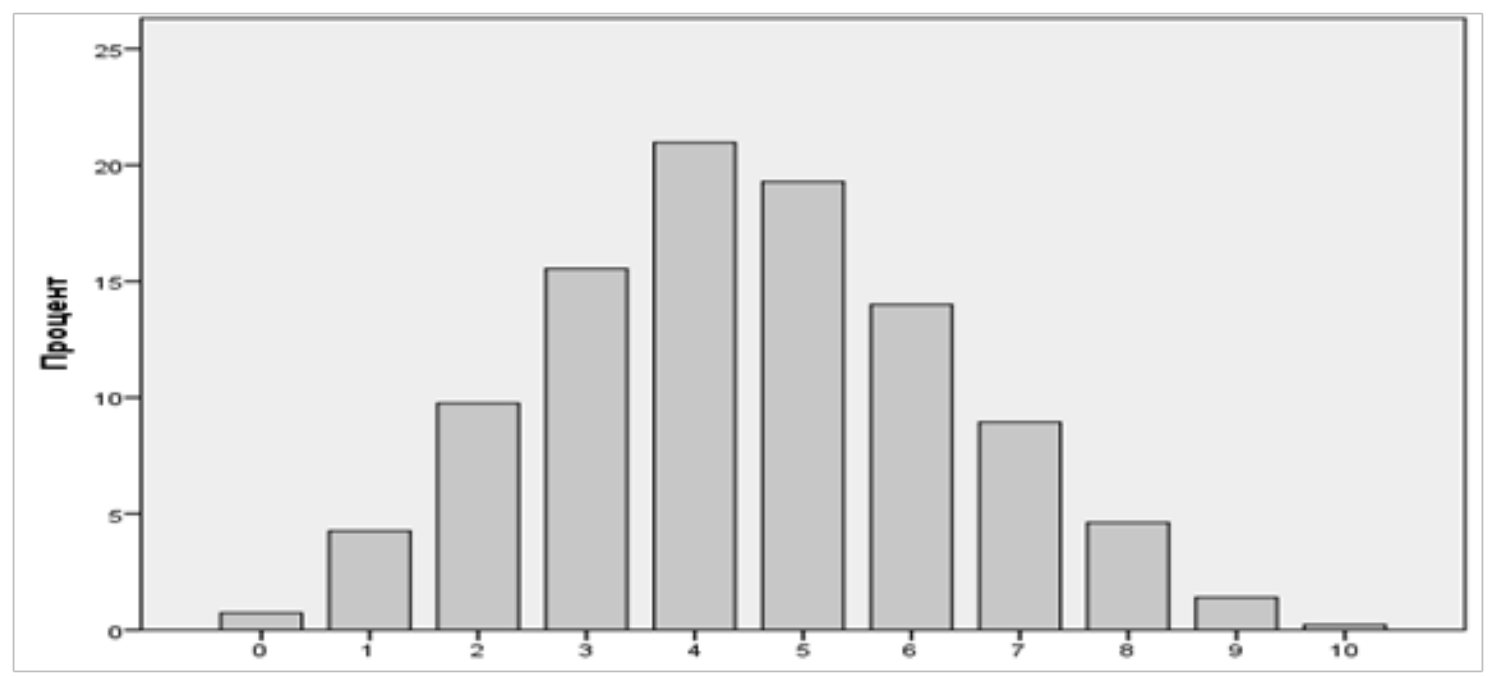

Рис. 2. Психологическая готовность к предпринимательской деятельности у молодых людей 19-30 лет: 0 - 10 - баллы. 


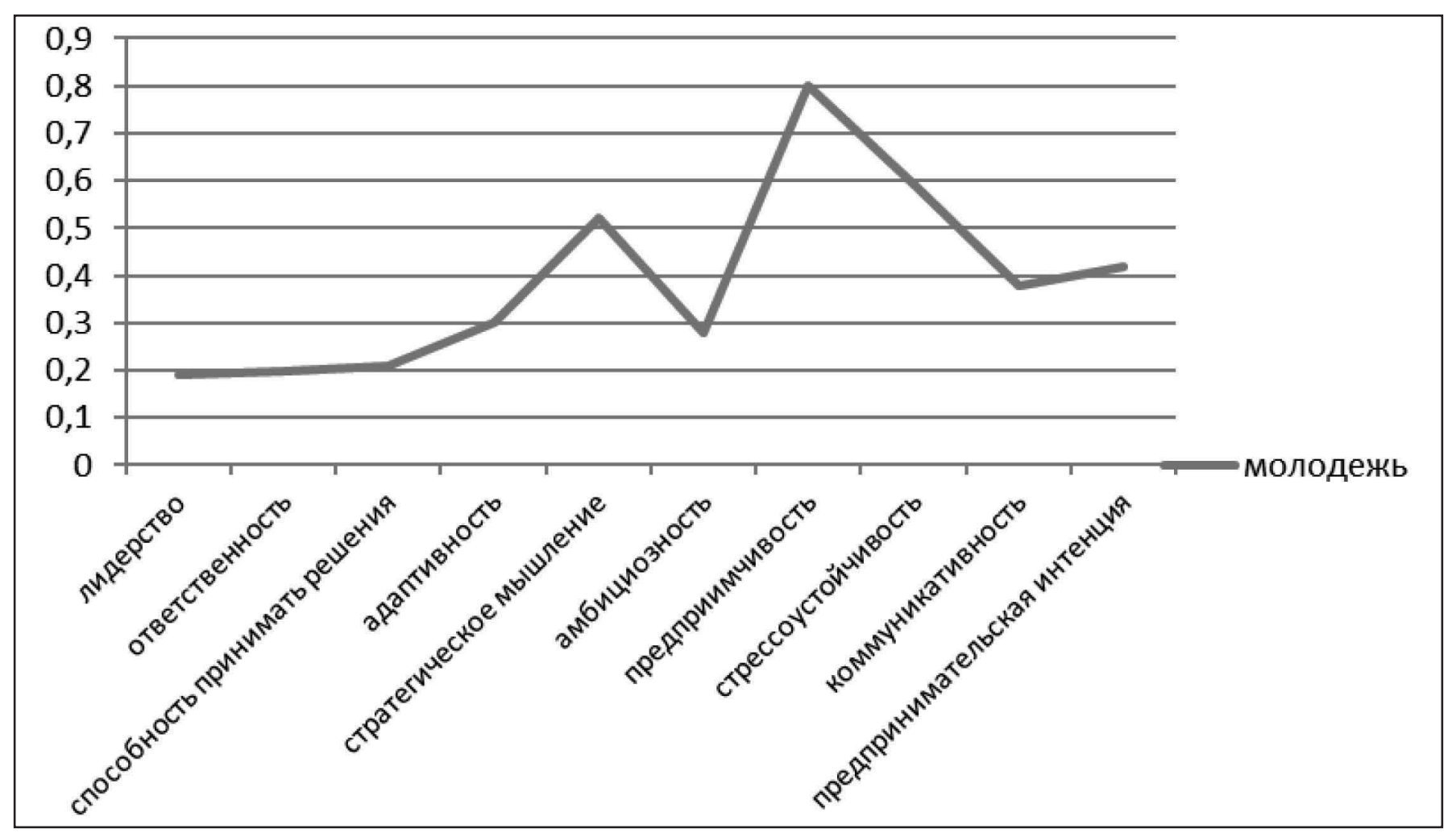

Рис. 3. Профиль выраженности профессионально важных для предпринимательской деятельности качеств у лиц 19-30 лет.

молодежи в Республике Хакасия. Также их можно использовать в процессе профессиональной подготовки студентов, например при проектировании содержания образовательных программ по разным направлениям подготовки в образовательном учреждении (для обоснования включения в учебный план дисциплин, направленных на развитие предпринимательской компе- тентности).

Результаты исследования показали, что разработанный и апробированный психодиагностический комплекс, сочетающий в себе проективные методы и анализ проблемных ситуаций, готов к использованию и может применяться в сфере малого бизнеса при профотборе.

\section{ЛИТЕРАТУРА}

1. Алтухов В. Оценка потенциала к предпринимательской деятельности // Кадровик. - 2012. - № 6. - С. 198 - 200.

2. Камнева Е.В., Анненкова Н.В., Кисловская Е.В. Представления студентов о российском предпринимателе // Экономическая психология и поведенческая экономика в условиях глобальных социальных и экономических изменений: материалы Всероссийской научной конференции. 17 - 21 ноября 2014 года, Москва. М.: Спутник +, 2014, с. 15-18.

3. Кастосов М.А., Иванова Н.Ю. Предпринимательские способности как фактор экономического роста // Вестник Московского университета. Серия 21. Управление (государство и общество). - 2006. - № 1. - С. 1-8.

4. Китова Д.А., Ханова 3.Г. Психологические особенности представлений студентов о предпринимательской деятельности / Актуальные проблемы социальной психологии и психологии профессиональной деятельности: коллективная монография / под редакцией Д.А. Китовой, 0.И. Каяшевой. СПб.: НИЦ APT, 2015. C. 12.

5. К Климова Е.К. Профессиональная деятельность предпринимателя. Психология успеха. - Спб.: Издательско-Торговый Дом «Скифия», 2014. - 208с.С. 186-199.

6. Мамедсупиев М.Д. Оценка качества трудового потенциала // ЭКО. -2009. - № 5. -С. 173-181.

7. Митрухина С.В. Личностные качества, определяющие склонность к предпринимательской деятельности// Modern Science. - 2020. - №8-1. -C. 299-305.

8. Митрухина С.В. Склонность к предпринимательской деятельности как объект социально-психологического исследования в социально-исторической ретроспективе // Modern Science. - 2020. - №6-4. - С. 123-128.

9. Теребова С.В., Плешаков П.С. Предпринимательские способности населения: понятие и измерение // Russian Journal of Education and Psychology. 2012. 
№9. URL: https://cyberleninka.ru/article/n/predprinimatelskie-sposobnosti-naseleniya-ponyatie-i-izmerenie (дата обращения: 27.09.2020).

10. Хлопова Т.В., Дьякович М.П. К оценке трудового потенциала предприятия // Социс. - 2003. - № 3. - С. 67-74.

11. Чекмарева Е.А. Оценка предпринимательской способности населения // Экономические и социальные перемены: факты, тенденции, прогноз. - 2009. № 2. - С. 85-92.

12. Райгородский Д.Я. Практическая психодиагностика. Методики и тесты. учебное пособие. Самара: Издательский Дом «БАХРАХ», 1998.

13. Алексеев А.А., Громова Л.А. Психогеометрия для менеджеров. Ленинград, Знание, 1991.

(c) Фотекова Татьяна Анатольевна (fotekova@yandex.ru), Митрухина Светлана Владимировна (mitruhina_lana80@mail.ru), Власова Евгения Николаевна (vlasova6510@gmail.com ), Федорова Анжелика Алексеевна (alis151@yandex.ru ),

Мантикова Анна Владимировна (anetdomanet@mail.ru).

Журнал «Современная наука: актуальные проблемы теории и практики»

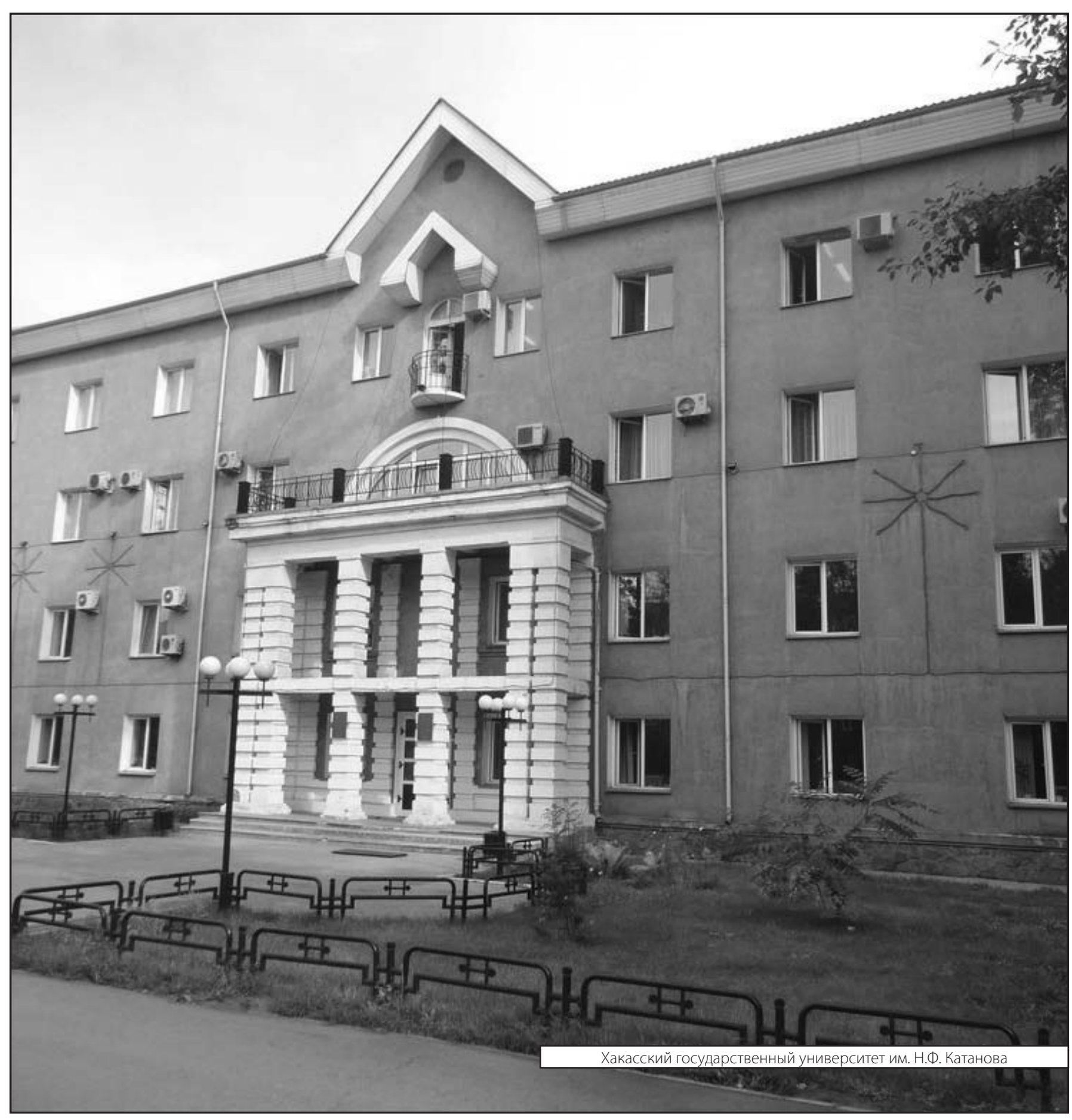

